\title{
FREQUENCY OF RISK FACTORS LEADING TO ACUTE RESPIRATORY INFECTIONS AMONG CHILDREN UNDER TWO YEAR'S AGE AND THEIR GENDER AND AGE WISE COMPARISON
}

\author{
Nighat Musa1, Riaz Gul², Yasir Mehmood', Saira Afridi ${ }^{3}$ \\ 1. Kabir Institute of Public Health, Peshawar \\ 2. North West School of Medicine, Peshawar \\ 3. Sardar Begum Dental College
}

\section{ABSTRACT}

\section{OBJECTIVE}

To determine the frequency of different risk factors leading to Acute Respiratory Infections among children under two years

To determine the most susceptible age group and to compare frequency of disease in both genders

\section{METHODOLOGY}

Study design was cross sectional observational. Duration of the study was three months (September November 2014. Study was conducted in two tertiary care hospitals of Peshawar namely Khyber Teaching hospital \& Hayatabad Medical Complex. A total of 200 children under 2 years of age who were attending outpatient department of two tertiary hospitals of Peshawar were studied. After getting consent from parents of children, data was collected from parents. A semi structured questionnaire was used as study tool. Pilot study was conducted prior to the actual study to check the feasibility of questionnaire. Children with acute respiratory tract infections were included in the study while immune compromised and children with other serious systemic diseases were excluded from the study Data was presented in the form of tables and graphs.

\section{RESULTS}

Frequency of acute respiratory infections was common among males (65\%) as compare to female children under two year of age. The most susceptible age group was found to be less than 06 months (46\%), then is 7-12 months (33\%). Environmental risk factors found to be involved in cases of ARI were poverty (73.5\%), rural residency with poor cross ventilation in houses (poor or no cross ventilation 66\%), no or partial immunization was $35 \%$ with malnutrition of sick children $76 \%$ may contribute to development of illness more quickly than other children. Illiteracy among mothers (78\%) and 39\% among fathers

\section{CONCLUSIONS}

$A R I$ is more common in infants less than 6 months of age and males are more affected as compared to female children. Poor socioeconomic status, Illiteracy, poor or no cross ventilation in houses, poor immunization status and malnutrition are the key risk factors.

\section{KEY WORDS}

Acute respiratory infections, risk factors, gender

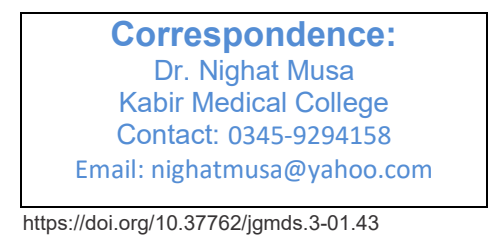




\section{INTRODUCTION}

Acute respiratory infections (ARI) are one of the most common public health problems and are one of the leading cause of illness and death of children under 5 years of age. Acute respiratory infections (ARI) constitute $30-60 \%$ of patients in outpatient department of pediatric units. Among these children $80 \%$ of them have upper acute respiratory infections; most of them are self-limiting and require symptomatic treatment except for throat and ear infections ${ }^{1}$. WHO estimates that in the year 2015 approximately 5.9 million children died below the age of 5 years. Among them $45 \%$ were newborns with neonatal mortality rate of $19 / 1000$ live births. The major cause of post natal deaths was respiratory infections (pneumonia), diarrhea and injuries ${ }^{2}$. The incidence of ARIs is especially high among infants, children, and the elderly and is more pronounced in low- and middleincome countries ${ }^{3,4}$. According to annual health report by Pakistan Medical Association in 2011, one child dies every one minute in Pakistan from EPI (expanded program on immunization) diseases, diarrhea and acute respiratory infections. According to the report most of children suffering from acute respiratory infections are those who has weak immune system because of the malnutrition ${ }^{5}$. In Khyber Pukhtunkhwa province District Health Information System report 2014 reports that, respiratory infections contribute to $39 \%$ among all the diseases and when it comes to the communicable diseases then the acute respiratory diseases contribute more than half of the total communicable diseases burden $(58 \%)^{6}$.

Studies on risk factors for acute respiratory infections showed that there are different risk factors which contribute to the development of the disease apart from its own causative agents. These risk factors are smoking, immune compromised states such as HIV, crowding, housing, and child care ${ }^{7}$. Not much data is available on different environmental risk factors which help in development of acute respiratory infections in Khyber Pukhtunkhwa therefore; this study was designed to analyze different factors which contribute in development of diseases among children. The main purpose of this study was to identify different risk factors involved in causation of acute respiratory tract infections in children of both genders and to recommend measures for its prevention so that children can be saved from the morbidity and mortality of this disease.

\section{METHODOLOGY}

It was a simple descriptive observational study conducted on 200 children attending outpatient department of pediatric unit of two tertiary care hospitals of Peshawar. This study was conducted for duration of three months from September to November 2014. Non probability convenient sampling technique was used. Children less than 2 years of age group and having Acute Respiratory Infection symptoms coming to Pediatric OPD of these two tertiary care hospitals were included in the study and those children who were having cardiac diseases and immunecompromised were excluded from the study. Gomez classification was used to assess malnutrition. Weight of every child was assessed with age by standard weight charts. Poverty is defined as not having enough money to meet the basic needs for individual including food.

Pilot study was done on $10 \%$ sample size to check feasibility and applicability of the questionnaire. Data was collected from parents of sick children after taking a verbal consent, on a semi structured questionnaire. Sample size was calculated using WHO sample size calculator. Results were presented in form of graph and tables. 


\section{RESULTS}

Data analysis of 200 cases of acute respiratory infection showed that $65 \%$ male children suffered from the disease as compare to $35 \%$ female children (table 01). According to age group distribution, disease was more common under 6 months of age (46\%), 33\% between 7-12 months, $14 \%$ between $13-18$ months and only $7 \% 19-24$ months of age were affected (table 02 ). Table 03 shows the different risk factors for acute respiratory infections. Majority of the children belonged from rural area $72 \%$ and $28 \%$ were from urban area. Out of 200 ARI patient's mothers, $78 \%$ children mothers were illiterate and $39 \%$ fathers were illiterate. $73.5 \%$ parent's household income was less than PKR 15000/month, 19\% had PKR 15001-35000/month and only $7.5 \%$ were having equal to more than PKR 35001/month. Regarding house condition, data showed that $69 \%$ were living in mud house and $39 \%$ had cemented house. Further analysis of data showed that $44 \%$ of houses had good cross ventilation system as compare to $46 \%$ of houses which were having either poor or no cross ventilation. Question regarding people living in one room, $59 \%$ of children parents told that 24 people live in one room, $38 \%$ showed $5-7$ people living in one room and $3 \%$ had 8 or more than 8 people living in one room. Feeding history revealed that $86 \%$ were breast fed and only $14 \%$ were bottle fed. Immunization status was $65 \%$ had complete according to age vaccination done whereas, $35 \%$ were either partially vaccinated or not vaccinated at all. Regarding the nutritional status $76 \%$ were under weight, $20 \%$ were normal, $4 \%$ were obese. Tables of results:

Table 1: Gender wise frequency distribution

\begin{tabular}{|l|l|l|}
\hline Gender & Frequency & Percent \\
\hline Male & 130 & $65 \%$ \\
\hline Female & 70 & $35 \%$ \\
\hline Total & 200 & 100 \\
\hline
\end{tabular}

Table 2: Age wise distribution of ARI in children under 02 years

\begin{tabular}{|l|l|l|}
\hline Age in months & Frequency & Percent \\
\hline Less than 06 months & 92 & $46 \%$ \\
\hline $\mathbf{7 - 1 2}$ months & 66 & $33 \%$ \\
\hline $\mathbf{1 3 - 1 8}$ month & 28 & $14 \%$ \\
\hline $\mathbf{1 9 - 2 4}$ months & 14 & $07 \%$ \\
\hline Total & 200 & 100 \\
\hline
\end{tabular}


Table 3: Environmental risk factors leading to ARI.

\begin{tabular}{|c|c|c|c|}
\hline \multicolumn{2}{|l|}{ Risk factors } & Frequency & Percent \\
\hline \multirow[t]{2}{*}{ Residency } & Rural & 144 & $72 \%$ \\
\hline & Urban & 46 & $28 \%$ \\
\hline \multirow[t]{2}{*}{ Maternal education } & Illiterate & 156 & $78 \%$ \\
\hline & Literate & 44 & $28 \%$ \\
\hline \multirow[t]{2}{*}{ Father education } & Illiterate & 78 & $39 \%$ \\
\hline & Literate & 122 & $61 \%$ \\
\hline \multirow[t]{3}{*}{ Household income } & Less than 15,000 & 147 & $73.5 \%$ \\
\hline & $15001-35000$ & 38 & $19 \%$ \\
\hline & 35001 and above & 15 & $7.5 \%$ \\
\hline \multirow[t]{2}{*}{ Feeding } & Bottle & 28 & $14 \%$ \\
\hline & Breast & 172 & $86 \%$ \\
\hline \multirow[t]{2}{*}{ House condition } & Mud house & 138 & $69 \%$ \\
\hline & Cemented & 78 & $39 \%$ \\
\hline \multirow[t]{2}{*}{ Cross Ventilation } & Good & 88 & $44 \%$ \\
\hline & Poor or absent & 132 & $66 \%$ \\
\hline \multirow[t]{3}{*}{ People living in one room } & $2-4$ & 118 & $59 \%$ \\
\hline & $5-7$ & 76 & $38 \%$ \\
\hline & 8 and above & 06 & $3 \%$ \\
\hline \multirow[t]{2}{*}{ Father smoking status } & Yes & 38 & $19 \%$ \\
\hline & No & 162 & $81 \%$ \\
\hline \multirow[t]{2}{*}{ Immunization status } & $\begin{array}{l}\text { Complete } \\
\text { Immunization } \\
\text { according to age }\end{array}$ & 130 & $65 \%$ \\
\hline & $\begin{array}{l}\text { No or partial } \\
\text { immunized }\end{array}$ & 70 & $35 \%$ \\
\hline \multirow[t]{3}{*}{ Nutritional status } & Under weight & 152 & $76 \%$ \\
\hline & Normal weight & 40 & $20 \%$ \\
\hline & Over weight & 08 & $4 \%$ \\
\hline
\end{tabular}

\section{DISCUSSION}

Data analysis of the study showed that males (65\%) are more affected from acute respiratory infections than the female children (35\%). A similar study was conducted in India in which they found very little difference between both genders. In their study they found that females $(27 \%)$ are more affected than the male children $(25.6 \%)^{8}$. Our study findings also showed that $79 \%$ of cases were below 12 month of age. Majority of children were less than 6 months making $46 \%$ of the total cases. Study conducted in Assam, India showed that prevalence of acute respiratory infections was more common in children less than one year of age. Another study done in Tikrit, Iraq also showed that acute respiratory infections are more common in children between aged 2 months - 11 months ${ }^{8,9}$. A study done in Tikrit general hospital, Iraq showed strong association between parents' education and occurrence of ARI. The protective effect of parental education against acute respiratory infection was awareness and care practices ${ }^{9}$.Same findings were found in our study that majority of mothers were illiterate $(78 \%)$ and $39 \%$ fathers were also having low educational status. 
Wang $\mathrm{J}$ et al and Oddy $\mathrm{W}$ in their two different studies showed positive association between breast feeding and respiratory infections especially upper tract infections ${ }^{10,11}$. Another study done in Dhaka also showed strong association between breast feeding and respiratory infections ${ }^{12}$. In this current study breast feeding was not found to be significantly protective against the development of ARI because $86 \%$ cases were breast fed and only $14 \%$ were bottle fed. Different studies and documents have proven that underweight Infants and children appeared to have significant association with ARIs occurrence and severity. ${ }^{12,13,14}$. These finding showed similar results to our study that found that $76 \%$ children suffering from Acute Respiratory infections included in the study were underweight. Hence low socioeconomic status, poor immunization, poor educational status of parents, breast feeding pattern, all plays a combined role in causation of Acute Respiratory Infections.

\section{CONCLUSION}

The frequency of ARI was found to be more in male children as compared to female children and the frequency of ARI was more in children of both genders less than six months of age. Low socioeconomic status, parent's education, living in poor ventilated houses, malnourishment (underweight), and incomplete immunization may act as environmental risk factors for development of acute respiratory infections.

\section{RECOMMENDATIONS}

On the basis of results of this study, the following recommendations are made to reduce the burden of disease in the community. Health promotion of the children by encouraging breast feeding of children by mothers, complete immunization of the children, proper weaning food, personal hygiene, cross ventilation at home and providing clean and safe environment for the children.

\section{REFERENCES}

1. Akbar P, Respiratory disorders. Basis of pediatrics. $8^{\text {th }}$ edition, Pakistan. 2014: $p 271$.

2. World health statistics, Child mortality. World Health Organization. Geneva. 2016: $p 48$.

3. The world health report 2004: changing history. Geneva, World Health Organization, 2004 (http://www.who.int/whr/2004/en/).

4. Nair $\mathrm{H}$ et al. Global burden of respiratory infections due to seasonal influenza in young children: a systematic review and meta-analysis. Lancet. 2011; 378:1917-1930.

5. Annual health report 2011, Pakistan Medical Association.

6. District Health Information System KPK, evidence based decision making 2014: p3-5

7. Tumwesigire SG, Barton T. Environmental risk factors for acute respiratory infections among children of military personnel in Uganda. East African Medical Journal. 1995 May;72(5):290-4.

8. Islam F, Sarma R, Debroy A, Kar S, Pal R. profiling acute respiratory tract infections from Assam, India. J Glob Infect Dis. 2013 Jan-Mar; 5(1): p8-14. 
9. Yousif TK, Khaleeq BA. Epidemiology of acute respiratory tract infections (ari) among children under five years old attending tikrit general teaching hospital. Middle east journal of family medicine. 2006; 4 (3) (http://www.mejfm.com/journal/May2006/epidemiology.htm\#T1)

10. Wang J, Dogaru C, Pescatore A, Jurca M, Beardsmore C, Kuehni C. Association of breast feeding and respiratory infections in infants. European respiratory journal. 2014; 44; P3454

11. Oddy W, Sly P, De Klerk NH, Landau L, Kendall G, Holt $P$ and Stanley F. Breast feeding and respiratory morbidity in infancy: a birth cohort study. Arch Dis Child. 2003 Mar; 88(3): 224-228.

12. Arifeen $S^{1}$, Black RE, Antelman G, Baqui A, Caulfield L, Becker S. Exclusive breastfeeding reduces acute respiratory infection and diarrhea deaths among infants in Dhaka slums. Pediatrics. 2001 Oct;108(4):E67 (http://www.ncbi.nlm.nih.gov/pubmed/11581475)

13. Alasfoor D, Traissac P, Gartner A and Delpeuch F. Determinants of Persistent Underweight among Children, Aged 6-35 Months, after Huge Economic Development and Improvements in Health Services in Oman. J Health PopulNutr. 2007 Sep; 25(3): 359-369.

14. Child hood and maternal under nutrition (chapter 4). World health report 2002; 109-1112

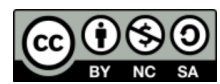

LICENSE: JGMDS publishes its articles under a Creative Commons Attribution Non-Commercial Share-Alike license (CC-BY-NC-SA 4.0) COPYRIGHTS: Authors retain the rights without any restrictions to freely download, print, share and disseminate the article for any lawful purpose. It includes scholarly networks such as Research Gate, Google Scholar, LinkedIn, Academia.edu, Twitter, and other academic or professional networking sites. 